\title{
Pengaruh Kinerja Lingkungan, Corporate Governance Pada Pengungkapan Corporate Social Responsibility
}

\author{
Gusti Ayu Putu Wulan Rahmasari \\ Faculty of Economics and Business, Mahasaraswati University \\ e-mail: rahmasari.wulan@gmail.com
}

How to cite (in APA style):

Rahmasari, G, A, P, W. (2020). Pengaruh Kinerja Lingkungan, Corporate Governance Pada Pengungkapan Corporate Social Responsibility. Warmadewa Management and Business Joural, 2(1) pp.102-111

\begin{abstract}
This research examines the influence of environmental performance, institutional ownership, managerial ownership of corporate social responsibility disclosures by using mining companies incorporated in the Indonesia Stock Exchange (IDX) and also listed in PROPER. The sample collection method in this study used the purposive sampling method and The sample meets the criteria of research is as much as 55 samples during the period of 2014-2018. The Data available is then processed using multiple regression analysis techniques.

The results of the research were seen from the test value of T test that has been done and resulted in significant value that has been shown that environmental performance has an influence on CSR disclosure. Significant results are also obtained in managerial performance variables stating this variable affects CSR disclosures. While the institutional ownership variables have a significant value greater than 0.05 resulting from the outcome, institutional ownership is stated to have no effect on CSR disclosures.
\end{abstract}

Keywords: environmental performance, institutional ownership, managerial ownership and corporate social responsibility disclosure.

\section{PENDAHULUAN}

Indonesia merupakan salah satu negara produsen mineral terbesar di dunia. Berdasarkan data Badan Pusat Statistik 2017, industri pertambangan di Indonesia memiliki efek multiflier yang mampu memicu pertumbuhan sektor industri lain terkait serta menyediakan lapangan pekerjaan bagi setidaknya 1,39 juta orang. Namun, dibalik kontribusi tersebut, melimpahnya SDA seringkali diiringi dengan munculnya berbagai permasalahan terhadap lingkungan sekitarnya. Pemerintah melalui Kementrian Lingkungan Hidup membentuk Program (PROPER) yang telah dilaksanakan mulai tahun 2002 dibidang pengendalian dampak lingkungan untuk meningkatkan program pelestarian lingkungan hidup. Hal ini menunjukkan bahwa perusahaan tidak hanya harus memperhatikan stockholders dan bondholders, melainkan juga kepada stakeholder. Stakeholder menuntut perusahaan untuk melakukan suatu tindakan yang berwujud pertanggungjawaban akan dampak yang ditimbulkan dari usahanya, dan upaya-upaya perusahaan dalam mengatasi dampakdampak tersebut. Hal ini dapat terwujud dengan melakukan tanggung jawab sosial perusahaan (corporate social responsibility), selanjutnya dalam tulisan berikutnya disebut CSR. Aspek pertanggungjawaban sosial ini dapat diungkapkan didalam laporan tahunan atau dilaporkan dalam bentuk pertanggungjawaban social perusahaan yang merupakan salah satu elemen laporan secara keseluruhan. Brammer, S. (2006) menyatakan bahwa pengungkapan CSR berkaitan dengan dampak lingkungan merupakan langkah yang dilakukan perusahaan untuk mengurangi regulasi 
yang merugikan tekanan legislatif dimasa depan.

Penerapan CSR dalam perusahaan bukan hanya kewajiban pihak internal saja, namun dalam praktik, setiap elemen perusahaan juga diharapkan berkontribusi dalam mewujudkan tujuan tersebut. Perusahaan diharapkan dapat menerapkan tata kelola perusahaan, guna menjaga keseimbangan antar pihak, yaitu internal dan eksternal. Corporate governance atau tata kelola perusahaan dapat diartikan sebagai suatu sistem yang dapat mendorong akuntabilitas dan transparasi perusahaan, sehingga dapat memberikan keuntungan secara menyeluruh kepada masyarakat. Dua komponen yang sangat penting dalam mendukung tata kelola perusahaan yang baik tersebut adalah kepemilikan instutional yang diasumsikan akan membantu dalam mendorong perusahaan untuk lebih melakukan pengungkapan CSR karena tuntutan dari pihak institusi untuk lebih luas dalam pengungkapan informasi perusahaan khususnya terkait dengan sosial, lalu kepemilikan majerial yang terdiri dari kepemilikan saham oleh pihak manajemen, hal ini akan membuat manajemen melakukan segala upaya untuk menjaga kinerja perusahaan agar tidak mengalami kerugian dan meningkatkan nilai perusahaan, salah satunya dengan pelaksanaan $C S R$ untuk meningkatkan kualitas perusahaan dimata stakeholders dan juga calon investor agar tertarik menanamkan modal ke perusahaan.

Terkait dengan permasalahan diatas, Penelitian ini akan menggunakan sampel perusahaan tambang karena perusahaan tambang merupakan salah satu usaha yang berpengaruh besar terhadap lingkungan dan keberlangsungan hidup sekitar. Adapun tujuan penulisan ini adalah untuk menganalisa pengaruh dari kinerja lingkungan serta penerapan GCG terhadap pengungkapan CSR.

\section{TELAAH LITERATUR DAN KAJIAN PUSTAKA}

Penelitian ini menggunakan 3 teori. Teori pertama adalah teori pengungkapan yang menyatakan bahwa pengungkapan sebagai penyajian informasi dengan alat selain laporan keuangan, dan berbeda dengan konsep pengakuan yang dianut laporan keuangan. Informasi ini menyediakan penjelasan yang lebih lengkap mengenai posisi keuangan, hasil operasi dan kebijakan perusahaan. Teori kedua adalah Teori Stakeholder yang mengasumsikan bahwa eksistensi perusahaan ditentukan oleh para stakeholdersnya (Devina, 2004). Teori stakeholder juga memberikan analisis tentang siapa kelompok yang menjadi penerima untuk tindakan CSR, dan penekanan pada pertemuan kebutuhan dan harapan dari kelompok stakeholders yang lebih luas (Nwanji, T. I., \& Howell, 2007). Teori stakeholder secara eksplisit mempertimbangkan pengaruh harapan berbagai kelompok stakeholders yang berbeda dalam masyarakat terhadap kebijakan pengungkapan yang dimiliki perusahaan. Teori ketiga adalah Teori Keagenan yang menjelaskan adanya hubungan antara manajemen dan pemilik yang memiliki kepentingan berbeda. Teori keagenan menurut Jensen dan Meckling 1976 dalam (Ratih dan Damayanthi, 2016) memaparkan adanya pemisahan hak milik perusahaan dan pertanggung jawaban atas pembuatan keputusan. Teori keagenan ditekankan untuk mengatasi dua permasalahan yang dapat terjadi dalam hubungan keagenan yaitu yang pertama saat keinginan dan tujuan antara principal dan agen berbeda dan yang kedua untuk memverifikasi tentang suatu masalah antara principal dan agent (Cahyani, 2009)

\section{Pengaruh Kinerja Lingkungan terhadap Pengungkapan CSR}

Kinerja lingkungan merupakan suatu upaya yang dilakukan perusahaan untuk menjaga lingkungan sekitarnya. Sudaryanto (2011) mengatakan bahwa perusahaan dengan kinerja lingkungan yang baik perlu mengungkapkan informasi kuantitas dan mutu lingkungan yang lebih baik dibandingkan perusahaan dengan perusahaan yang memiliki kinerja lingkungan yang buruk. Hasil penelitian sebelumnya dalam (Syaiful, 2016) mengungkapkan adanya pengaruh signifikan 
antara kinerja lingkungan dengan corporate social responsibility.

Berdasarkan penelitian tersebut, maka hipotesis pertama penelitian ini dirumuskan :

H1 : Kinerja lingkungan berpengaruh positif terhadap CSR.

\section{Pengaruh Kepemilikan Institusional terhadap Pengungkapan CSR}

Kepemilikan institusional dapat meningkatkan keputusan perusahaan dalam pengungkapan tanggung jawab sosial. Persentase kepemilikan instusional yang tinggi diharapkan dapat membuat perusahaan mengungkapkan perusahaan lebih luas. Penelitian Jayanti, dkk (2018) menunjukkan bahwa terdapat pengaruh positif antara kepemilikan institusional terhadap CSR. Berdasarkan asumsi tersebut dan penelitian sebelumnya maka hipotesis ketiga pada penelitian ini adalah :

$\mathrm{H} 2$ : Kepemilikan instusional berpengaruh positif terhadap CSR.

\section{Pengaruh Kepemilikan Manajerial terhadap Pengungkapan CSR}

Kepemilikan majerial dalam suatu perusahaan dapat menyebabkan berkurangnya tindakan manajemen laba dari pihak manajer. Pihak manajer akan mengambil keputusan sesuai dengan kondisi perusahaan, seperti melakukan pengungkapan CSR untuk meningkatkan nilai perusahaan. Hasil penelitian (Rawi, 2009) juga mendukung pengaruh positif antara kepemilikan manajerial terhadap CSR. Berdasarkan asumsi tersebut dan penelitian sebelumnya maka hipotesis ketiga pada penelitian ini adalah :

H3 : Kepemilikan majerial berpengaruh positif terhadap $\boldsymbol{C S R}$.

\section{METODE PENELITIAN}

\section{Lokasi Penelitian}

Sesuai dengan karakteristik masalah yang diteliti penelitian ini menggunakan data perusahaan pertambangan di Bursa Efek Indonesia periode 2014-2018.

Populasi dan Sampel Populasi pada penelitian ini merupakan perusahaan tambang, dengan pengambilan sampel pada perusahaan tambang yang telah terdaftar di bursa efek indonesia pada periode 2014-2018 yang telah mempublikasi laporan tahunan dan pengungkapan CSR secara lengkap serta telah terdaftar pada PROPER periode 2014-2018.

\section{Jenis Data}

Sumber data dalam penelitian ini adalah data sekunder yaitu berupa annual report pada periode 2014-2018 dan data ini termasuk kedalam jenis data kuantitatif

\section{Teknik Analisis Data $C S R$}

Corporate social responsibility dalam penelitian ini diproksikan dalam indeks pengungkapan tanggung jawab sosial. Rumus yang digunakan untuk menghitung CSR adalah rumus perhitungan CSRI adalah sebagai berikut (Sembiring, 2005):

$$
\operatorname{CSRI}_{j}=\frac{\sum \mathrm{X}_{\mathrm{ij}}}{n_{j}}
$$

\section{Kinerja Lingkungan}

Kinerja lingkungan dalam penelitian ini akan diukur melalui presentasi perusahaan dalam mengikuti PROPER. Sistem penilaian kinerja PROPER mencakup pemeringkat dalam 5 warna yaitu : Emas (skor 5), Hijau (skor 4), Biru (skor 3), Merah (skor 2) dan Hitam (skor 1).

Corporate Governance Pada penelitian ini, peneliti akan mengambil proksi variabel kepemilikan 
manajerial, ukuran dewan komisaris, kepemilikan institusional dan komite audit. Maka rasio-rasio yang akan digunakan untuk meneliti variabel yang bersangkutan adalah :

\section{Kepemilikan Instusional :}

Kepemilikan institusional merupakan proporsi kepemilikan saham oleh institusi dalam hal ini institusi pendiri perusahaan, bukan institusi pemegang saham publik. Rumus untuk menentukan persentase kepemilikan institusional adalah :

\section{$\underline{\Sigma}$ Saham Institusional

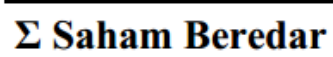

\section{Kepemilikan Majerial :}

Kepemilikan manajerial merupakan tingkat kepemilikan saham pihak manajemen yang secara aktif ikut dalam pengambilan keputusan perusahaan (direktur dan komisaris). Rumus untuk menentukan persentase kepemilikan majerial adalah :

\section{$\underline{\text { Saham milik manajemen }}$ \\ $\Sigma$ Saham beredar}

\section{HASIL DAN PEMBAHASAN Analisis Deskriptif}

\section{Uji Analisis Deskriptif} Tabel 1.1

\begin{tabular}{|c|c|c|c|c|c}
\hline \multicolumn{6}{|c}{ Descriptive Statistics } \\
\hline & $\mathrm{N}$ & Min & Max & Mean & $\begin{array}{c}\text { Std. } \\
\text { Deviation }\end{array}$ \\
\hline CSR & 55 & 31.00 & 53.00 & $\begin{array}{c}411.45 \\
5\end{array}$ & 613.556 \\
\hline Kinerja Lingkungan & 55 & .00 & 5.00 & 34.000 & .95452 \\
\hline $\begin{array}{c}\text { Kepemilikan } \\
\text { Institusional }\end{array}$ & 55 & .04 & .99 & .3793 & .32618 \\
\hline $\begin{array}{c}\text { Kepemilikan } \\
\text { Manajerial }\end{array}$ & 55 & .00 & .66 & .0987 & .21638 \\
\hline Valid N (listwise) & 55 & & & & \\
\hline
\end{tabular}

Berdasarkan hasil analisis deskriptif diatas menunjukkan Corporate Social Responsibility (CSR) sebagai variabel dependen memiliki rata rata pengungkapan sebanyak 411,455 dengan pengungkapan CSR terendah sebesar 31,00 dan yang tertinggi sebesar 53,00. Variabel kinerja lingkungan yang diukur dengan melihat laporan hasil PROPER yang diselenggarakan oleh Kementrian Lingkungan Hidup menunjukan rentang nilai dari 0 hingga 5 yang berarti bahwa 0 merupakan nilai terendah sedangkan 5 merupakan nilai tertinggi untuk kinerja lingkungan. Nilai rata-rata pada variabel ini adalah 34,00. Jika dikonversikan berdasarkan warna kategori PROPER, rata-rata peringkat yang diraih oleh sampel perusahaan pada laporan hasil PROPER berada pada kriteria warna biru. Dan pada PROPER periode 2014-2018 perusahaan yang

berturut turut mendapat peringkat emas adalah PT. Bukit Asam Tbk, sedangkan PT. Aneka Tambang Tbk hanya pernah meraih peringkat emas pada tahun 2017. Sedangkan nilai terendah 
0 dalam kinerja lingkungan menunjukan bahwa tidak ada perusahaan yang berada pada kriteria hitam atau yang berarti memiliki masalah dalam pengelolan lingkungan.

Kepemilikan instusional yang memiliki rata rata 0,32618. Nilai terendah dan nilai tertinggi memiliki rentan nilai dari 0,04 hingga 0,99 . Kepemilikan manajerial yang memiliki rata rata 0,0987. Nilai terendah dan tertinggi berada di rentah nilai dari 0 hingga 0,66 .

\section{Hasil Analisis Data Uji Normalitas}

\section{One Sample Kolmogorov Smirnov}

Tabel 1.2

\begin{tabular}{|l|l|r|}
\hline \multicolumn{2}{|c|}{} & $\begin{array}{c}\text { Unstandardized } \\
\text { Residual }\end{array}$ \\
\hline $\mathrm{N}$ & Mean & 55 \\
\hline $\begin{array}{l}\text { Normal } \\
\text { Parameters }\end{array}$ & Std. Deviation & .0000000 \\
\cline { 2 - 3 } & Absolute & 530.443 .302 \\
\hline $\begin{array}{l}\text { Most } \\
\text { Differences }\end{array}$ & Positive & .104 \\
\cline { 2 - 3 } & Negative & .083 \\
\hline Test Statistic & & -.104 \\
\hline Asymp. Sig. (2-tailed) & .104 \\
\hline
\end{tabular}

Sumber: SPSS Output

Hasil uji normalitas dengan menggunakan Kolmogorov-Smirnov menunjukkan bahwa nilai Asymp. Sig. (2-tailed) sebesar 0.200. Nilai ini lebih besar dari signifikan 0,05 sehingga dapat disimpulkan bahwa data mengikuti sebaran normal. Oleh karena itu asumsi normalitas pada regresi telah terpenuhi.

\section{Uji Multikolinieritas}

\section{Hasil Uji Multikolinieritas}

\section{Tabel 1.3}

\begin{tabular}{|l|c|c|}
\hline \multirow{2}{*}{ Model } & \multicolumn{2}{|c|}{ Collinearity Statistics } \\
\cline { 2 - 3 } & Tolerance & VIF \\
\hline (Constant) & & \\
\hline Kinerja Lingkungan & .846 & 1.182 \\
\hline Kepemilikan Institusional & .840 & 1.190 \\
\hline Kepemillikan Manajerial & & \\
\hline & & 1.282 \\
\hline
\end{tabular}

Sumber: SPSS Output 
Tabel diatas menunjukkan bahwa untuk semua variabel independen yang digunakan memiliki nilai toleransi lebih besar dari 0,10, Kinerja Lingkungan (X1) sebesar 0,846, Kepemilikan Institusional (X2) sebesar 0,840 dan Kepemilikan Manajerial (X3) sebesar 0,780.

Nilai VIF yang dihasilkan kurang dari 10, Kinerja Lingkungan (X1) sebesar 1,182, Kepemilikan Institusional (X2) sebesar 1.190 dan Kepemilikan Manajerial (X3) sebesar 1,282 sehingga dapat disimpulkan bahwa tidak terjadi korelasi ganda (multikolinieritas) antar variabel independen. Oleh karena itu asumsi multikolinieritas telah terpenuhi.

\section{Uji Autokorelasi}

\section{Hasil Uji Autokorelasi}

Tabel 1.4

\begin{tabular}{|c|c|c|c|c|c|}
\hline Model & $\mathbf{R}$ & R Square & $\begin{array}{l}\text { Adjuste } \\
\text { d R } \\
\text { Square }\end{array}$ & $\begin{array}{c}\text { Std. } \\
\text { Error of } \\
\text { the } \\
\text { Estimate }\end{array}$ & $\begin{array}{l}\text { Durbin- } \\
\text { Watson }\end{array}$ \\
\hline 1 & $.503^{a}$ & .253 & .209 & 545.822 & .698 \\
\hline
\end{tabular}

\section{Sumber: SPSS Output}

Tabel diatas menunjukan Nilai Durbin Watson (DW) sebesar 0,698. Berdasarkan tabel Durbin-Watson dengan N 55 dan banyak variabel bebas 3 diperoleh nilai upper boung (dU) sebesar 1,681 dan 4 - dU sebesar 2,319, nilai DL sebesar 1,452. Dapat dilihat nilai DW tidak berada di antara batas atau upper boung (dU) dan 4- dU, dan nilai DW sebesar 0.698 lebih kecil dari nilai DL 1.452 dengan demikian maka $\mathrm{H}_{0}$ ditolak atau terjadi Autokorelasi.

\section{Uji Heteroskedastisitas}

\section{Hasil Uji Heteroskedastisitas}

\section{Tabel 1.5}

\begin{tabular}{|c|c|c|c|c|c|}
\hline \multirow{2}{*}{ Model } & \multicolumn{2}{|c|}{$\begin{array}{l}\text { Unstandardized } \\
\text { Coefficients }\end{array}$} & \multirow[t]{2}{*}{$\begin{array}{l}\text { Standardized } \\
\text { Coefficients }\end{array}$} & \multirow{2}{*}{$t$} & \multirow{2}{*}{ Sig. } \\
\hline & $\mathrm{B}$ & Std. Error & & & \\
\hline (Constant) & 3.307 & 1.760 & & 1.879 & .066 \\
\hline $\begin{array}{c}\text { Kinerja } \\
\text { Lingkungan }\end{array}$ & .756 & .424 & .237 & 1.784 & .080 \\
\hline $\begin{array}{l}\text { Kepemilikan } \\
\text { Institusional }\end{array}$ & $\begin{array}{c}- \\
3.592\end{array}$ & 1.243 & -.385 & -1.089 & .106 \\
\hline $\begin{array}{c}\text { Kepemilikan } \\
\text { Manajerial }\end{array}$ & $\begin{array}{c}- \\
2.114\end{array}$ & 1.946 & -.150 & -1.087 & .282 \\
\hline
\end{tabular}

Sumber: SPSS Output

Jika model tersebut diuji secara parsial maka Tabel diatas menunjukkan bahwa semua variabel bebas yang digunakan pada penelitian memiliki nilai lebih besar dari 0,05 sehingga dapat disimpulkan bahwa tidak terjadi heterokedasitas. 


\section{Uji Analisis Data Uji Statistik t}

Penelitian ini menggunakan Analisis Regresi Linier Berganda untuk mengetahui hubungan positif atau negatif dari variable terkait.

\section{Uji Analisis Data}

\section{Tabel 1.6}

\begin{tabular}{|l|r|r|r|r|r|}
\hline \multirow{2}{*}{ Model } & \multicolumn{2}{|c|}{$\begin{array}{c}\text { Unstandardized } \\
\text { Coefficients }\end{array}$} & \multirow{2}{*}{$\begin{array}{c}\text { Standardized } \\
\text { Coefficients }\end{array}$} & \multirow{2}{*}{$\mathrm{t}$} & \multirow{2}{*}{ Sig. } \\
\cline { 2 - 4 } & \multicolumn{1}{|c|}{$\mathrm{B}$} & Std. Error & & & \\
\hline (Constant) & 34.208 & 3.517 & & 9.727 & .000 \\
\hline $\begin{array}{l}\text { Kinerja } \\
\text { Lingkungan }\end{array}$ & 2.024 & .846 & .315 & 2.392 & .021 \\
\hline $\begin{array}{l}\text { Kepemilikan } \\
\text { Institusional }\end{array}$ & 2.201 & 2.484 & .117 & .886 & .380 \\
\hline $\begin{array}{l}\text { Kepemilikan } \\
\text { Manajerial }\end{array}$ & -7.879 & 3.887 & -.278 & -2.027 & .048 \\
\hline
\end{tabular}

\section{Sumber: SPSS Out}

Maka dari hasil analisis diatas konstanta dan koefisien regresi yang diperoleh apabila dimasukkan pada rumus persamaan umum regresi adalah sebagai berikut :

\section{$\mathrm{CSR}=34.208+2.024 \mathrm{KL}+2.201 \mathrm{KI}-7.879 \mathrm{KM}+\mathrm{e}$}

\section{Pengujian Hipotesis}

\section{Uji Simultan (Uji F)}

Tabel 1.7

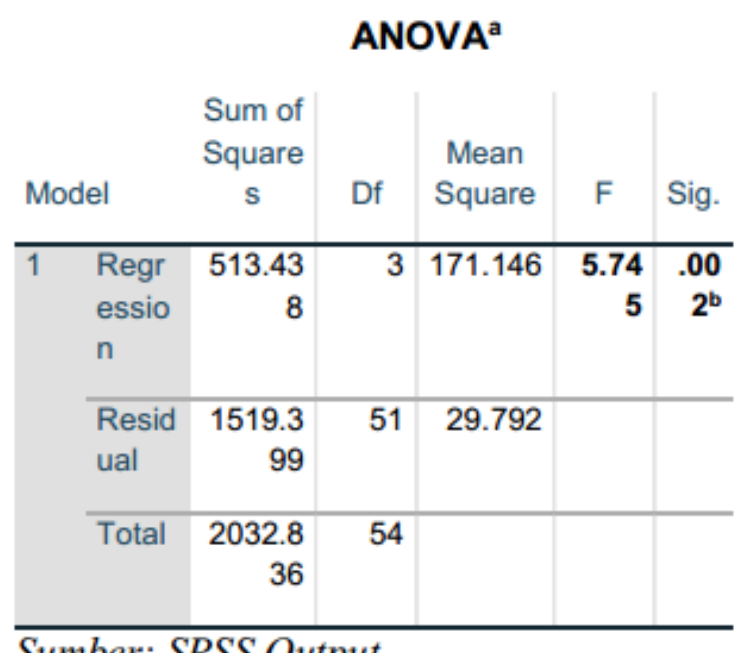

Sumber: SPSS Output

Pada Tabel tersebut dapat dilihat nilai signifikan sebesar $0,002<0,05$ atau nilai $\mathrm{F}$ hitung sebesar 5,745> F table sebesar 2,79 maka menunjukkan bahwa variabel independen yang digunakan yaitu variabel Kinerja Lingkungan, Kepemilikan Institusional dan Kepemilikan Manajerial berpengaruh signifikan terhadap CSR secara simultan.

\section{Koefisien Determinasi $\left(\mathbf{R}^{2}\right)$}




\section{Uji Determinasi (R2)}

Tabel 1.8

Model Summary

\begin{tabular}{|c|c|c|c|c|c|}
\hline Model & $\mathrm{R}$ & $\begin{array}{c}\mathrm{R} \\
\text { Square }\end{array}$ & $\begin{array}{c}\text { Adjusted } \\
\text { R } \\
\text { Square }\end{array}$ & $\begin{array}{c}\text { Std. } \\
\text { Error of } \\
\text { the } \\
\text { Estimate }\end{array}$ & $\begin{array}{l}\text { Durbin- } \\
\text { Watson }\end{array}$ \\
\hline 1 & $.503^{\mathrm{a}}$ & .253 & .209 & 545.822 & .698 \\
\hline
\end{tabular}

Nilai koefisien yang diperoleh adalah sebesar 0,209. Nilai determinasinya menjadi 0,09x 100\% $=$ 20,9\%. Hal ini mengindikasikan bahwa CSR (Y) dijelaskan sebesar 20,9\% oleh Variabel Kinerja Lingkungan (X1), Kepemilikan Institusional (X2) dan Kepemilikan Manajerial (X3) sisanya dijelaskan oleh variabel lain yang tidak dimasukkan ke dalam model atau penelitian.

\section{PEMBAHASAN}

Pengaruh Kinerja Lingkungan terhadap Corporate Social Responsibility.

Berdasarkan hasil analisis diatas diketahui 0,021 yang berarti lebih kecil dari 0,05 sehingga H1 diterima. Jadi sesuai dengan hasil diatas untuk variabel kinerja lingkungan dinyatakan berpengaruh secara positif dan signifikan terhadap pengungkapan CSR. Ditinjau dari hasil tersebut dapat disimpulkan bahwa pada periode 2014-2018 perusahaan tambang telah melakukan pengelolaan dengan baik untuk lingkungan yang terkena dampak dari kegiatan operasionalnya. Tentu ini mampu menunjukan bahwa perusahaan tambang tidak hanya sebatas melakukan ekplorasi dan eksploitasi bagi lingkungan namun juga secara seimbang memperbaiki dan mengelola lingkungan sesuai dengan kebutuhan lingkungan tersebut. Hasil ini selaras dengan penelitian dari Anindito, dkk (2012) yang juga menemukan adanya pengaruh kinerja lingkungan terhadap pengungkapan CSR, peneliti mengungkapkan bahwa perusahaan yang memiliki kinerja lingkungan yang baik akan mengungkapkan CSR yang lebih luasPengaruh Kepemilikan Institusional terhadap Corporate Social Responsibility.

Nilai signifikan kepemilikan institusional adalah sebesar 0,287 dimana hasil tersebut lebih besar dari 0,05 yang berarti H2 ditolak. Jadi sesuai dengan hasil diatas untuk variabel kepemilikan instusional dinyatakan tidak berpengaruh terhadap pengungkapan CSR. Dilihat dari hasil analisis tersebut menunjukan bahwa para investor dari institusi yang menanamkan modal ke perusahaan tidak menjadikan masalah pengungkapan tanggung jawab sosial sebagai tolak ukur sebelum menanamkan modalnya, sehingga para investor tersebut tidak menuntut perusahaan dalam mengungkapkan informasi terkait tanggung jawab sosialnya ke dalam laporan keuangan. Jadi besar atau kecilnya persentase kepemilikan saham institusional ke perusahaan tidak akan berpengaruh terhadap luasnya pengungkapan CSR. Hasil ini mendukung hasil penelitian dari Djuitaningsih (2012) yang menunjukan tidak adanya pengaruh dari kepemilikan instusional terhadap pengungkapan CSR, hal ini bisa disebabkan karena investor dari institusi yang telah menanamkan modal ke perusahaan tidak terlalu mempertimbangkan mengenai masalah tanggung jawab sosial yang telah dilakukan perusahaan, sehingga institusi tidak menuntut perusahaan untuk mengungkapkan CSR secara rinci pada laporan tahunan.

Pengaruh Kepemilikan Manajerial terhadap Corporate Social Responsibility.

Nilai siginifikan kepemilkan manajerial adalah 0,045 dimana hasil tersebut lebih besar dari 
0,05 yang berarti $\mathrm{H} 3$. Jadi sesuai dengan hasil diatas untuk variabel kepemilikan majerial dinyatakan berpengaruh terhadap pengungkapan CSR. Hasil ini mendukung hasil dari penelitian Rawi (2009) yang menyatakan adanya pengaruh antara kepemilikan manajerial dengan luas pengungkapan CSR. Kepemilikan saham oleh pihak manajemen akan membuat perusahaan lebih luas melakukan pengungkapan CSR. semakin tinggi kepemilikan majerial maka semakin tinggi juga tingkat pengungkapan CSR yang akan dilakukan. Hal ini dilakukan manajer untuk meningkatkan kualitas perusahaan agar dapat memberikan nilai positif dimata calon investor agar tertarik untuk menanamkan modal ke perusahaan.

\section{KESIMPULAN}

Berdasarkan hasil penelitian diatas dapat disimpulkan bahwa variabel kinerja lingkungan berpengaruh terhadap pengungkapan CSR, ini dapat diartikan bahwa legtimasi yang diberikan masyarakat oleh perusahaan, secara tidak langsung telah menuntut perusahaan untuk memperhatikan lingkungan sekitar, oleh karena itu perusahaan lebih banyak melakukan pengelolaan terkait lingkungan untuk memenuhi legtimasi perusahaan dimata masyarakat. Pada hasil uji variabel kepemilikan manajerial telah menunjukan bahwa kepemilikan manajerial berpengaruh terhadap CSR. Hal ini bisa disebabkan karena rata rata kepemilikan saham majerial dalam suatu perusahaan sudah cukup besar, sehingga pihak manajemen dapat secara maksimal melaksanakan kegiatan CSR. Sedangkan untuk hasil uji variabel kepemilikan institusional menunjukan bahwa, kepemilikan institusional tidak berpengaruh terhadap CSR. Kondisi ini menunjukan bahwa kepemilikan institusi di Indonesia tidak menjadikan tanggung jawab sosial sebagai kriteria utama sebelum menanamkan modal pada suatu perusahaan, kemungkinan besar hal ini karena keuntungan masih dijadikan tolak ukur utama sebelum melakukan investasi.

\section{DAFTAR PUSTAKA}

Anindito, Tito, dan Ariyanto, M. D. (2012). Pengaruh Kinerja Lingkungan Terhadap Corporate Social Responsibility Discloure dan Kinerja Finansial Perusahaan Kimia dan Pertambangan yang terdapat di BEI (periode : 2007-2010). Diponegoro Journal Of Accounting, 2(1).

Brammer, S., S. P. (2006). Voluntary environmental disclosure by large UK companies. Journal of Bussiness Finance \& Accounting, 33(7, 8), 1168-1188.

Cahyani, N. (2009). Good Corporate Governance Dalam Persperktif Teori Agensi. Jurnal Dinamika Keuangan Dan Perbankan, 1(1).

Devina, F. L. S. dan Z. (2004). Pengaruh Karakteristik Perusahaan terhadap Pengungkapan Sosial dalam Laporan Tahunan Perusahaan Go Public di Bursa Efek Jakarta. Jurnal Manajemen Dan Akuntansi \& Sistem Informasi, 4, 161-177.

Djuitaningsih,Tita dan Marsyah, W. A. (2012). Pengaruh Manajemen Laba dan Mekanisme Corporate Governance terhadap CSR Discloure. Media Akuntansi, 2(2).

Jayanti, Karina Ries., dan Husaini, A. (2018). Pengaruh Good Corporate Governance dan ProfitabilitasTerhadap Pengungkapan Corporate Social Responsibility (Studi pada Perusahaan Sektor Pertambangan Yang Terdaftar DI BEI Tahun 2015-2016).

Nwanji, T. I., \& Howell, K. (2007). Shareholdership, stakeholdership and the modern global business environment: A survey of the literature. Journal of Interdisciplinary Economics, 18(4), 347-361.

Ratih, I Dewa Ayu., dan Damayanthi, I. G. A. E. (2016). Pengaruh Manajerial dan Profitabilitas pada Nilai Perusahaan dengan Pengungkapan Tanggung jawab Sosial sebagai Variabel Pemoderasi. E-Jurnal Akuntansi Universitas Udayana, 14(2).

Rawi. (2009). Pengaruh Kepemilikan Manajemen,Institusi, Dan Leverage Terhadap Corporate 
Social Responsibility Pada Perusahaan Manufaktur Yang Listing Di Bursa Efek Indonesia. Sembiring, E. R. (2005). Karakteristik perusahaan dan pengungkapan tanggung jawab sosial: studi empiris pada perusahaan yang tercatat di Bursa Efek Jakarta. Simposium Nasional Akuntansi VIII, 379-395.

Sudaryanto. (2011). Pengaruh kinerja lingkungan terhadap finansial perusahaan dengan corporate social responsibility (CSR) disclosure sebagai variable intervening. Skripsi. Universitas Diponegoro.

Syaiful Bahri, dan F. A. C. (2016). Pengaruh Kinerja Lingkungan terhadap Corporate Financial Performance dengan Corporate Social Responsibility sebagai Variabel Intervening. (Studi Empiris pada Perusahaan Manufaktur yang Terdaftar di BEI). Jurnal Ekonomi Universitas Kediri, 1(2). 